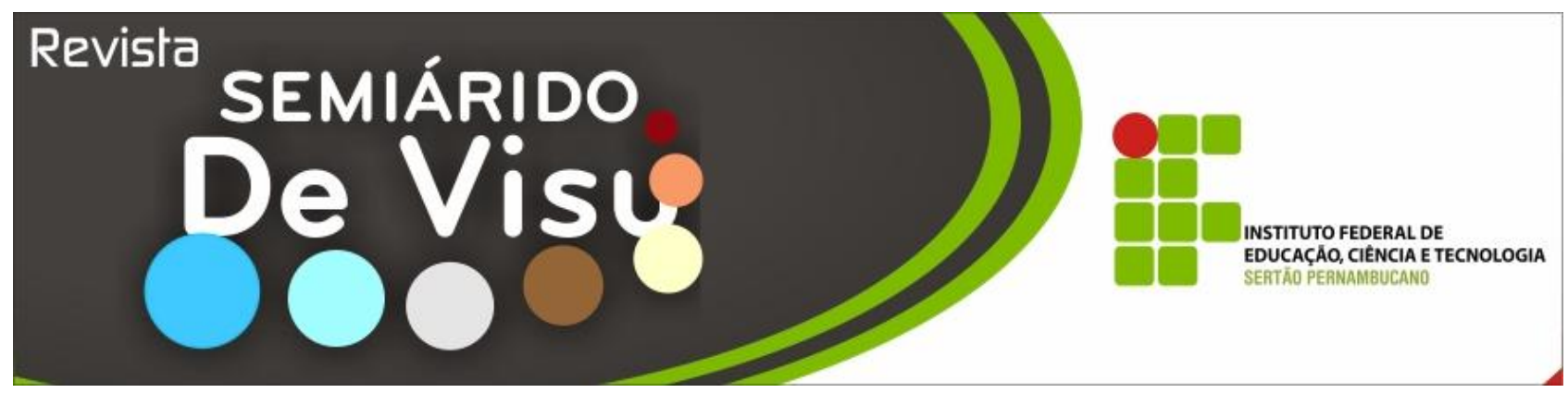

\title{
Processo de transferência e adaptação de tecnologia e conhecimento: o caso EMBRAPA Semiárido
}

\author{
Maria Gomes da Conceição Lira ${ }^{1}$, Brigitte Renata Bezerra de Oliveira ${ }^{2}$ \\ ${ }^{1}$ Administradora do Instituto Federal de Educação, Ciência e Tecnologia Sertão Pernambucano - Reitoria - Fone: (87) \\ 21014327 - e-mail: maria.lira@ifsertao-pe.edu.br \\ 2 Prof ${ }^{a}$ da Universidade Federal Rural de Pernambuco (UFRPE)- e-mail:
}

\begin{abstract}
RESUMO: O objetivo geral desse estudo é analisar o papel da Embrapa Semiárido no desenvolvimento socioeconômico do polo Petrolina/Juazeiro com foco no processo de transferência de tecnologias. O arcabouço teórico é constituído pela contextualização histórica do Nordeste, seus indicadores sociais e as alternativas de convivência com a seca através de Arranjos Produtivos Locais, políticas públicas e Inovações tecnológicas. A pesquisa é qualitativa de caráter exploratório, descritivo e analítico, do tipo estudo de caso na Embrapa Semiárido. A coleta de dados primários e secundários foi realizada utilizando a observação direta, análise documental e entrevistas semi-estruturadas, com representantes da sociedade e funcionários da instituição selecionada. A análise através da triangulação dos dados representa a descrição e interpretação das informações coletadas. Concluiu-se que a Embrapa Semiárido tem dado grandes contribuições para o desenvolvimento do Polo Petrolina/Juazeiro e que há necessidade de melhorias nas atividades de Transferência de Tecnologia por ela desenvolvida.
\end{abstract}

Palavras-chave: inovação, desenvolvimento, semiárido.

\section{Process of transfer and adaptation of technology and knowledge: the case EMBRAPA Semiarid}

\begin{abstract}
The general objective of this study is to analyze the work of Embrapa Semiarid in socio-economic development of the pole Petrolina/Juazeiro do with focus in the process of technology transfer. The theoretical framework consists of the historical context of the Northeast, its social indicators and the alternatives of coexistence with the drought through Local Productive Arrangements, public policies and technological innovations. The research and qualitative exploratory, descriptive and analytical type case study in Embrapa Semiarid. The collection of primary data and secondary was performed using direct observation, documentary analysis and semi-structured interviews with representatives of the company and employees of the institution selected. The analysis by means of triangulation of data represents the description and interpretation of information collected. It was concluded that the Embrapa Semiarid has given great contributions to the development of Polo Petrolina/Juazeiro and that there is a need for improvements in the activities of the transfer of technology it developed.
\end{abstract}

Key words: innovation, development, semiarid 


\section{Introdução}

$\mathrm{P}$ or muitos anos, a falta de oferta hídrica e os longos períodos de aridez foram motivo de debates políticos e sociais com intuito de resolver esta problemática da seca; uma solução encontrada foi a descoberta da real vocação econômica dessa região bem como o suporte para que essa vocação fosse explorada.

As vocações econômicas regionais vêm sendo identificadas, organizadas e desenvolvidas através de aglomerados conhecidos como arranjos produtivos locais (APLs) constituídos por empresas que em suas relações sinérgicas e com a ajuda de outros agentes do arranjo propiciam ganhos econômicos, sociais, tecnológicos. Outro termo usado nesse contexto é clusters, definido como:

\begin{abstract}
Concentrações geográficas de firmas setorialmente especializadas, principalmente de pequeno e médio porte, onde a produção tende a ocorrer verticalmente desintegrada, mantendo relações interfirmas de cooperativismo e competitividade à jusante e à montante (Crocco; Horácio, 2001, p. 4).
\end{abstract}

No semiárido nordestino existem diversos APLs, no qual destaca-se o APL da fruticultura irrigada, e fazem parte deste Aglomerado Produtivo diversos municípios do estado da Bahia e Pernambuco, abrangendo uma área de $46.651 \mathrm{Km}^{2}$ e uma população em torno de 682.206 habitantes. Oito cidades desse APL (Juazeiro, Casa Nova, Sobradinho,Curaçá, Petrolina, Lagoa Grande, Santa Maria da Boa Vista e Orocó) compõe a Região Integrada de Desenvolvimento (RIDE) - Polo Petrolina e Juazeiro. Essa RIDE criada em 2001, representa uma área de atuação prioritária de promoção de iniciativas e investimentos que reduzam suas desigualdades sociais e econômicas.

O reconhecimento da importância das inovações tecnológicas como elementos fundamentais para o desenvolvimento do Semiárido brasileiro trouxe para a região o Centro de Pesquisa Agropecuária do Trópico Semiárido - CPATSA, denominado Embrapa
Semiárido. Criada em 23 de junho de 1975, pelo Ministério da Agricultura e do Abastecimento, a instituição atua no Semiárido Tropical brasileiro com o objetivo de promover o desenvolvimento rural procurando conferir eficiência produtiva ao setor agropecuário. A participação da instituição em diminuir os impactos causados pelo clima e pela herança histórica de dominação nessa região ocorre através da pesquisa e da transferência de tecnologias adaptadas ao semiárido, sobretudo para fomentar a capacidade de crescimento agropecuário que as cidades integrantes do polo Petrolina e Juazeiro têm demonstrado.

A partir das considerações expostas, este trabalho busca conhecer a importância da Embrapa Semiárido para o desenvolvimento socioeconômico do polo Petrolina-PE e Juazeiro-BA, sobretudo na perspectiva da agricultura familiar, analisando seu processo de produção de conhecimento e transferência de tecnologia. Conforme destacado nas seções a seguir, ressalta-se que o debate teórico acerca desses conceitos de desenvolvimento, APLs, convivência com o semiárido, conhecimento e transferência de tecnologia é mais complexo do que o aparente, demonstrando ainda a relevância acadêmica da pesquisa.

\section{Fundamentação teórica}

Para que este trabalho atinja seus objetivos é imprescindível uma conceituação teórica acerca de temas como a questão histórica de dominação e pobreza da Região Nordeste, a delimitação do Semiárido brasileiro e as politicas públicas de convivência com o semiárido. Serão estudados também o desenvolvimento de APLs,e da fruticultura irrigada no Pólo Petrolina-Juazeiro. Por fim serão discutidos temas relacionados a pesquisa, conhecimento e inovação como agente de desenvolvimento apoiados em eficientes processos de transferência. 
Maria Gomes da Conceição Lira \& Brigitte Renata Bezerra de Oliveira

\section{- Alternativas de desenvolvimento para o Semiárido brasileiro}

A região Nordeste possui $1.558 .196 \mathrm{~km}^{2}$ de área e cerca de 51.534.406 habitantes (IBGE, 2007). Embora a região tenha apresentado crescimento notório, os avanços não são suficientes para evitar a lacuna entre a base econômica e a densidade populacional dessa região. Em toda literatura elaborada a respeito do Nordeste, sob a ótica do subdesenvolvimento, da problemática da seca e das longas estiagens remete-se automaticamente o Semiárido brasileiro (SAB). Félix e colaboradores (2007) descrevem a Região Semiárida:

O Semiárido brasileiro representa $11,39 \%$ do território nacional e abriga $29 \%$ da população do país. Possui uma extensão de $969.589,4 \mathrm{Km}^{2}$ que corresponde a $62 \%$ do território nordestino (incluindo a parte Semiárida de Minas Gerais). No Semiárido, vivem quase 21 milhões de pessoas, destacando que mais de 9 milhões (44\%) pertencem à zona rural, onde se encontram os mais pobres, com índices de qualidade de vida muito abaixo da média nacional.

Esta região apresenta os piores indicadores sociais do país decorrentes de uma complexa articulação entre condicionantes ambientais, socioeconômicos e políticos (CARVALHO E EGLER, 2003). A melhoria de vida no Semiárido deu-se através do desenvolvimento de suas potencialidades. A vocação econômica dentro da região Nordeste vem sendo trabalhada através do estudo de clusters ou Arranjos Produtivos Locais.

Toneto (2004) define clusters como: uma aglomeração setorial em uma dada região em que os atores estão articulados entre si e com outras instituições (centro de pesquisas, escolas técnicas, universidades, poder público,etc), compartilhando o desenvolvimento/realização de determinada atividade). Haddad (2004) apud Moraes (2005) disserta sobre a importância econômica dos Arranjos Produtivos Locais destacando o papel de alguns fatores como renda per capta, instrumentos de gestão, grau de educação, potencial de desenvolvimento.

Dentro do Semiárido os principais APLs baseiam-se na agropecuária. $O$ papel da agricultura para o desenvolvimento do Nordeste foi possível devido à adoção de tecnologias como a irrigação, considerada, desde meados do século XIX, a solução para os problemas da seca. Sua implantação ocorreu na prática através do Departamento Nacional de Obras Contra as Secas (DNOCS), que realizou as primeiras experiências de irrigação no Semiárido (CARVALHO E EGLER, 2003).

Neste contexto o APL da fruticultura Petrolina-Juazeiro se destacou frente às condições adversas do semiárido, gerando empregos e renda na região, além de demonstrar a eficácia de alternativas econômicas para o Nordeste (OLIVEIRA; XAVIER; COSTA, 2008). A fruticultura no polo Petrolina/Juazeiro se expressa em um conjunto de atividades, constituindo uma cadeia produtiva com um certo grau de complexidade (LACERDA E LACERDA, 2004). O APL está estruturado por empresas formais, informais e propriedades da agricultura familiar (fornecedoras de insumos, serviços tecnológicos, instituições de formação técnica e superior na área agrícola, empresas especializadas no embalamento e comercialização, órgãos públicos).

As políticas públicas voltadas para essa região também contribuíram significativamente para seu crescimento, sobretudo para agricultura de base familiar, predominante no SAB.

Para Bonnal e Maluf (2007) a formulação de políticas públicas agrícolas está embasada em três perspectivas: valorização dos papéis não produtivos da agricultura familiar, enfoque territorial e desenvolvimento sustentável. Apesar da forte interferência estatal no semiárido, as políticas públicas de apoio à produção agropecuária surtiram pouco efeito sobre o desenvolvimento rural e regional do SAB (SILVA E GUIMARÃES FILHO, 2006); a região ainda possui uma economia frágil resultante de questões política - cultural da região Nordeste. Portanto, torna-se necessário 
mais envolvimento da sociedade e órgãos federais para a criação de um novo Semiárido, baseado no conceito de convivência com a seca.

\section{- Desenvolvimento Sustentável: conhecimento e inovação tecnológica}

O Novo paradigma de Desenvolvimento Sustentável aparece como um novo modelo que concilia riqueza e desenvolvimento com preservação ambiental e combate a pobreza. Para tanto é importante antes de tudo a capacidade de ampliação da massa crítica dos recursos humanos, o domínio do conhecimento e da informação.

A literatura evidencia a importância do conhecimento como fonte de inovação e competitividade, bem como o papel das interações locais na produção e na difusão desse conhecimento. Segundo Lastres e Ferraz (1999), da aprendizagem resulta acumulação de conhecimentos, que por sua vez sustenta os avanços científicos, introduzindo as inovações que irão, de forma contínua, transformar o sistema econômico. Para Fleury e Fleury (2001) a gestão do conhecimento está imbricada aos processos de aprendizagem nas organizações. A aprendizagem esta que ocorre de fato quando o conhecimento compartilhado é de fato assimilado na vivência do indivíduo. (HILDRETH E KIMBLE, 2002 apud ALBAGLI E MACIEL, 2004).

Essa capacidade de conversão de conhecimento em ação representa o eficiente processo de transferência de tecnologias, onde o conhecimento tecnológico é repassado para um novo utilizador ocorrendo de fato a inovação tecnológica.

\section{Procedimentos metodológicos}

Como citado, este estudo se propõe a fazer uma análise da contribuição da Embrapa Semiárido para o SAB sob a perspectiva da transferência de tecnologia, para tanto, serão analisados os fatores relevantes neste processo.
Espera-se que o trabalho seja útil para a Empresa. Deste modo o trabalho é de natureza aplicada. Silva e Menezes (2001, p. 20) explicam que uma pesquisa se classifica como aplicada porque objetiva gerar conhecimentos para aplicação prática dirigidos à solução de problemas específicos. Envolve verdades e interesses locais.

Para atingir os objetivos desta pesquisa é necessário que haja investigação e um envolvimento com o tema em busca de se criar maior familiaridade com o ambiente e o fenômeno. Lakatos e Marconi (2001) dizem que em entrevistas exploratórias o pesquisador parte de uma hipótese e aprofunda seu estudo nos limites de uma realidade específica, buscando antecedentes, maiores conhecimentos para, em seguida, planejar uma pesquisa descritiva ou do tipo experimental.

A pesquisa é definida como qualitativa, método que enfatiza a especificidade de um fenômeno, quanto às suas origens e à sua razão de ser (HAGUETTE, 2001). Devido à natureza e os procedimentos utilizados, o estudo de caso é o método mais adequado a essa pesquisa porque é utilizado em muitas situações, para contribuir com o conhecimento que temos dos fenômenos individuais, organizacionais, sociais, políticos e de grupo, além de outros fenômenos relacionados (YIN, 2005).

A seleção da amostra deu-se primeiramente pela escolha: (a) da região foco do estudo: Polo Petrolina-Juazeiro, parte do APL fruticultura; (b) do processo a ser analisado: Transferência de tecnologia e conhecimento; e (c) da instituição foco: Embrapa Semiárido, referência em pesquisa agropecuária.

Os instrumentos de coleta de dados escolhidos foram a observação direta, análise documental e a entrevista semi-estruturada. Tanto a análise documental quanto a observação direta ajudaram na escolha do objetivo inicial do estudo. A escolha da empresa foi fortemente influenciada pelo vínculo existente entre ela e a pesquisadora, e este fator foi de grande contribuição para obtenção dos resultados. O objetivo da pesquisa documental foi obter a situação real dos 
processos de transferência de tecnologia da empresa. A análise documental ocorreu norteada nos seguintes documentos: Relatório de Gestão 2008, Plano Diretor - PDU 20082011-202, Relatório do Seminário de Estratégias para uma Gestão Municipal de Convivência com o Semiárido, informações consultadas no website da empresa.

A seleção da amostra foi nãoprobabilística intencional, de acordo com a afinidade dos sujeitos com a temática do estudo. As entrevistas foram formais, presenciais e individuais. Foram escolhidos dois funcionários da instituição, dentre eles o analista da área de transferência de tecnologia, uma professora, coordenadora dos cursos superiores do IF Sertão Pernambucano Campus Petrolina - Zona rural, um produtor rural, membro da Associação de Produtores Rurais de Petrolina e um representante da Secretaria de Desenvolvimento Rural de Petrolina.

Para análise dos dados, foi escolhido o método de comparação constate, de acordo com Merriam (1998), a partir das transcrições das entrevistas, das notas de observação e dos dados secundários coletados.

\section{Análise dos resultados}

Com base em pesquisa documental é possível afirmar a relevância e abrangência da pesquisa gerada pela empresa. Considerando os diversos segmentos do agronegócio, que compreende agricultura familiar e empresarial, entre outros setores sociais da região semiárida, cerca de 250.000 usuários sejam atendidos. Aproximadamente, $70 \%$ das localidades do Semiárido estão cobertas por ações de pesquisa, desenvolvimento e inovação desta Unidade (EMBRAPA, 2009a). A empresa possui como usuário/cliente e parceiros aproximadamente 200 instituições de diversos segmentos.

A entrevista semi-estruturada realizada neste estudo propocionou uma análise sobre a opnião tanto da sociedade como de funcionários da empresa sobre sua importância para o desenvolvimento regional.Os resultados confirmam a relevância da Embrapa Semiárido para o desenvolvimento do Pólo PetrolinaJuazeiro.

“O papel da Embrapa foi fundamental,
dificilmente nós teríamos hoje, por exemplo, a
fruticultura na pungência que tem se não fosse
o apoio das respectivas tecnologias geradas."
(entrevistado 2-pesquisador)
“(...)muito importante, pro desenvolvimento,
pelo menos pra gente que somos agricultor é
uma boa, porque muitas coisas que a gente não
sabe fica sabendo através dela”. (entrevistado
3-produtor)

Pela observação direta, análise de documentos institucionais e das entrevistas pôde-se concluir que a sociedade de modo geral percebe a contribuição da Embrapa para o desenvolvimento socioeconômico do polo em que está inserida. A análise documental demonstra essa importância através do desenvolvimento de pesquisas buscando alternativas racionais de cultivo, de criação e de extrativismo. O uso das tecnologias geradas pela pesquisa proporciona melhoria comprovada se for adaptada de maneira eficaz.

Todos os métodos de coleta utilizados buscaram obter informações sobre características, adequação, particularidades e eficácia bem como lacunas que esse processo pode vir a ter. O Relatório de gestão 2008 traz uma tabela com o quantitativo das atividades de Transferência de Tecnologia executadas pela Embrapa Semiárido no período 2007-2008. 
Maria Gomes da Conceição Lira \& Brigitte Renata Bezerra de Oliveira

Tabela 1. Atividades de Transferência de Tecnologia(TT) executadas pela Embrapa Semiárido no período 2007-2008

\begin{tabular}{|c|c|c|c|c|c|c|c|c|c|}
\hline \multirow[b]{2}{*}{ ATIVIDADE } & \multicolumn{3}{|c|}{2007} & \multicolumn{3}{|c|}{2008} & \multicolumn{3}{|c|}{ TOTAL } \\
\hline & Cuantidade & $\begin{array}{l}\text { Carga } \\
\text { horária }\end{array}$ & Participantes & Cuantidade & $\begin{array}{c}\text { Carga } \\
\text { horária }\end{array}$ & Participantes & Cuantidade & $\begin{array}{c}\text { Carga } \\
\text { horária }\end{array}$ & | Participantes \\
\hline $\begin{array}{l}\text { Exposiçðese } \\
\text { Feiras }\end{array}$ & 19 & - & - & 13 & - & - & 32 & - & - \\
\hline $\begin{array}{l}\text { Visitas } \\
\text { Técnicas }\end{array}$ & 56 & - & 953 & 115 & - & 2544 & 171 & - & 3497 \\
\hline Cursos & 66 & $9<2$ & 1841 & 56 & 998 & 1645 & 122 & 1940 & 3489 \\
\hline $\begin{array}{l}\text { Embrapa } \\
\text { Escola }\end{array}$ & 60 & - & 3300 & 38 & - & 3325 & 98 & - & 6625 \\
\hline Seminários & 45 & 199 & 2270 & 8 & 32 & 169 & 53 & 231 & 2439 \\
\hline Workshops & 5 & 56 & 256 & 3 & 66 & 61 & 8 & 122 & 317 \\
\hline Reuniöes & 19 & 72 & 748 & 10 & 76 & 391 & 29 & 148 & 1139 \\
\hline Fórurıs & 4 & 10 & 240 & - & - & - & 4 & 10 & 240 \\
\hline Simpósios & 1 & 16 & 300 & 2 & 36 & 510 & 3 & 52 & 810 \\
\hline $\begin{array}{l}\text { Jurnal Semi- } \\
\text { Árido }\end{array}$ & 4 & - & - & 2 & - & - & 6 & - & - \\
\hline $\begin{array}{l}\text { Dia də } \\
\text { Campo па TV }\end{array}$ & 3 & - & - & 2 & - & - & 5 & - & - \\
\hline $\begin{array}{l}\text { Programa } \\
\text { Prosa Rural }\end{array}$ & 5 & - & - & 4 & - & - & 9 & - & - \\
\hline
\end{tabular}

Fonte: Relatório de Gestão 2008, Embrapa Semiárido.

Quanto à organização dos eventos de um modo geral o gráfico mostra que nos últimos anos ocorreu um elevado nível de satisfação em relação à organização de eventos de comunicação para TT.
O nível de satisfação de bom a excelente para a organização dos eventos TT foi de $87,4 \%$ em 2006, 5,2 \% a menos que em 2004. Em 2008 esse percentual cresceu alcançando níveis $91,5 \%$ conforme gráfico abaixo.

Gráfico 1: Nível de satisfação do cliente sobre a organização de eventos de TT pela Embrapa Semiárido.

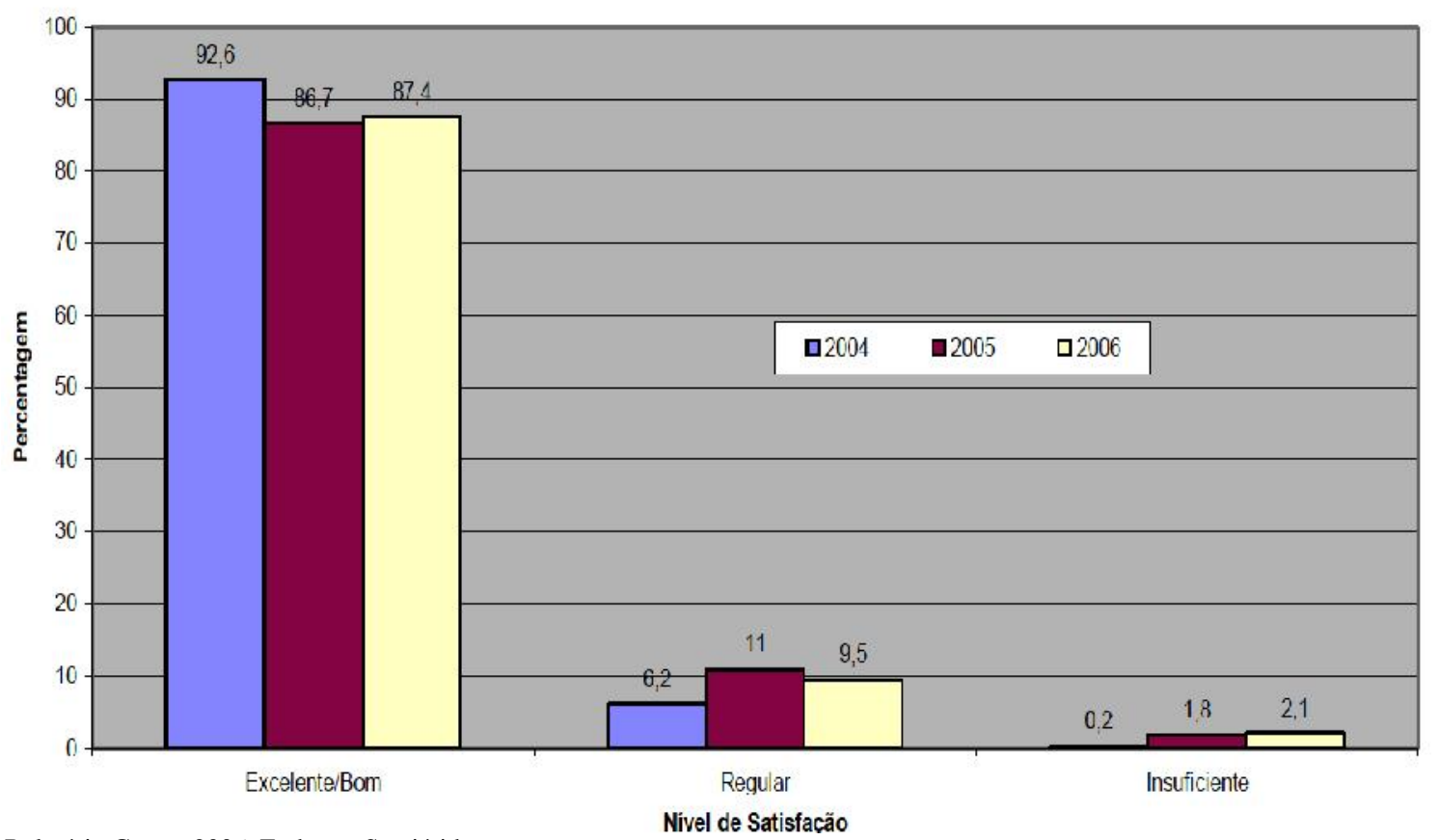

Fonte: Relatório Gestão 2006, Embrapa Semiárido 
Maria Gomes da Conceição Lira \& Brigitte Renata Bezerra de Oliveira

\begin{abstract}
Nas entrevistas e nos comentários e sugestões podemos destacar alguns comentários quanto às atividades de TT desenvolvidas:
\end{abstract}

“ E quanto às instalações, são ótimas e $o$ atendimento também é muito importante para que todos levem uma boa impressão, para seus estados e municípios." ( participanteseminário)

“ Sugiro que o próximo seja feito, em um auditório na própria cidade de Petrolina, facilitando o acesso e conforto a todos os participantes." ( participante-seminário)

“ Parabéns a Embrapa pela dedicação e empenho que tem demonstrado, assim como o compromisso que tem realizado, sobretudo com o semiárido." (participante-seminário).

Embora seja reconhecida por todos os segmentos da sociedade, a empresa estudada apresenta algumas limitações denotadas pelos entrevistados. A distancia do seu público-alvo, a falta de aplicabilidade de suas pesquisas, entre outros.

O trabalho de pesquisa da Embrapa é sim o melhor trabalho desse tipo prestado no Brasil, só precisa chegar numa proporção maior também desejada pela entidade para a agricultura familiar.” (participante-seminário)

“(...) em termos de transferência de tecnologia mesmo eu desconheço, apesar de ter o semiárido show, ainda é muito incipiente, pela dimensão que é feito lá dentro, fica muito lá dentro(...)" (entrevistado 4- prefeitura)

“(...)se tivesse como alguém da Embrapa que fosse na localidade diretamente a gente explicar, aí era uma boa (...)" (entrevistado 3produtor)

A Embrapa tem destinado muitos esforços a fim de minimizar a distancia da unidade com todo seu público-alvo, através por exemplo do uso de diversas atividades de transferência de tecnologia porém não é suficiente devido a abrangência do seu mandato institucional.

Revista Semiárido De Visu, v.2, n.2, p.274-284, 2012

\begin{abstract}
"Nós não temos a competência interna nem a missão de atender diretamente este públicoalvo, porque este público-alvo é um públicoalvo muito grande e muito disperso(...)" (entrevistado 5 - analista)

“ $O$ que nós vimos a partir da década de 80 é esfacelamento né da extensão rural, ela entra em uma profunda crise e fica esse vazio que a Embrapa tem feito o esforço muito grande para fazer algumas atividades de transferência.(...) (entrevistado 2-pesquisador)
\end{abstract}

Neste sentido pode-se afirmar que a Embrapa assumiu a competência de transferência de tecnologia, mas suas atividades ainda são muito incipientes. $O$ que ocorre portanto é apenas uma difusão que não garante adoção e incorporação da mesma. Quando existe incorporação de tecnologia pelo receptor do conhecimento pode-se dizer que houve inovação tecnológica.

\section{Conclusões}

Apesar dos enclaves climáticos e políticos existentes na sua área de atuação, a Embrapa Semiárido contribui ativamente para o desenvolvimento socioeconômico do polo Petrolina/Juazeiro sendo reconhecida por todos os agentes da sociedade (usuários/cidadãos, empresas, instituições de ensino, prefeituras, etc.) como uma empresa de grande importância na região.

Sua contribuição ocorre por meio da pesquisa agropecuária voltada para a sustentabilidade do agronegócio na fruticultura irrigada e, sobretudo na área de sequeiro. O resultado das pesquisas chega até a sociedade através de atividades de Transferência de Tecnologias realizadas pelo o setor de Comunicação e Negócios da Empresa. As atividades mais realizadas são os dias de campo, cursos e visitas técnicas a Unidade. Elas possuem bons níveis de satisfação quanto à organização, conteúdos e carga horária.

O que se pode perceber, porém, é que a sociedade representada nesta pesquisa pelos entrevistados de cada segmento, gostaria que a Embrapa Semiárido pudesse estar mais próxima do seu público-alvo. Para eles a 
distancia existente faz com que as tecnologias geradas não sejam adotadas por completo.

O debate conceitual realizado neste estudo a cerca da aprendizagem demonstrou que para que a transferência seja válida é preciso conscientização da necessidade de novas tecnologias por parte do receptor, tempo, linguagem adequada e acompanhamento in locu da utilização das tecnologias. A distancia citada nas entrevistas impossibilita a aprendizagem do conhecimento, a inovação tecnológica de fato.

Essa inovação ainda não ocorre devido à falta de intermediários entre a pesquisa e a sociedade. Esses intermediários seriam a extensão rural e a assistência técnica, que não é realizada pela Embrapa em larga escala porque ela não tem estrutura organizacional, física e principalmente pessoal para isso.

As sugestões a seguir para melhoria da TT na empresa foram feitas considerando o reconhecimento por parte da empresa da existência de lacunas nos processos de TT utilizados atualmente pela empresa estudada. As mudanças demandam tempo, recursos e uma nova visão da empresa dos processos de transferência. A compreensão desse problema passa indiscutivelmente pela necessidade de se executar uma estratégia de comunicação para a transferência de tecnologia, onde predominam novas formas de relacionamento entre três segmentos (agricultores, extensionistas e pesquisadores) muito mais baseadas no entendimento, na articulação, na divisão de responsabilidade e na cooperação que no domínio do conhecimento.

A estrutura ideal para fomentar uma nova TT na Embrapa Semiárido teria seus processos interligados, propondo que a pesquisa seja realizada em um contínuo processo de comunicação com a transferência de tecnologia respondendo as demandas do ambiente, representado na figura pelo Mercado.

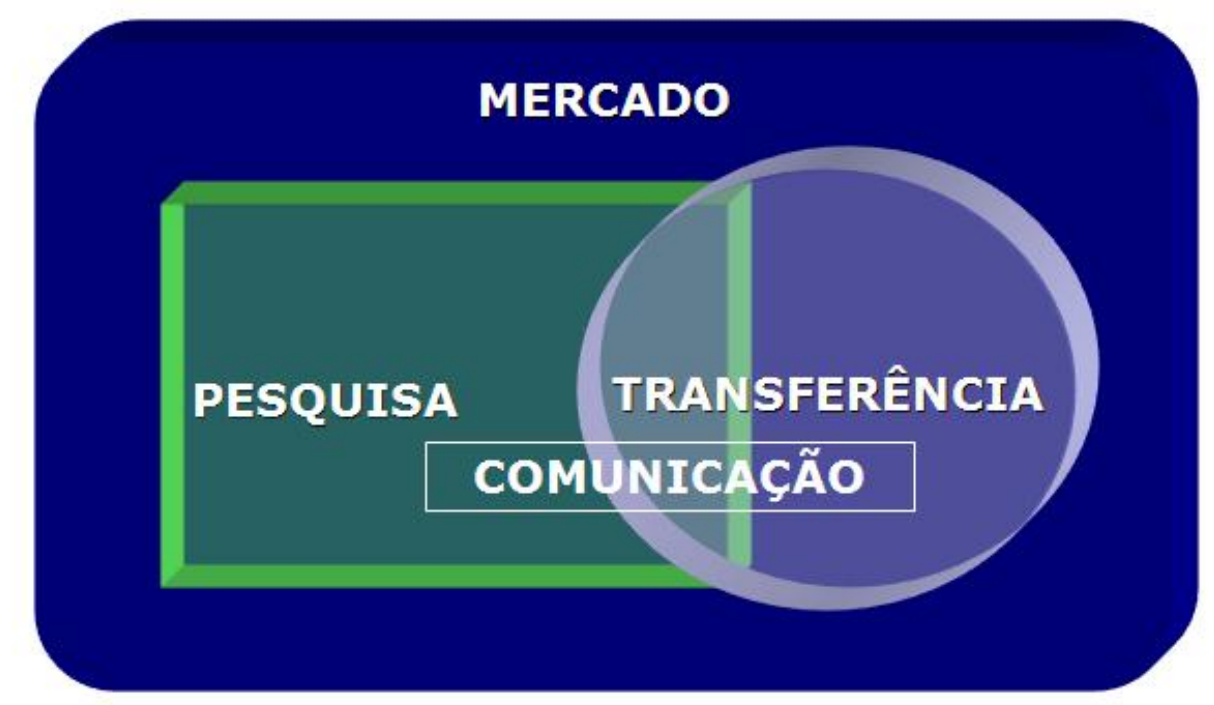

Figura 1: Processos interligados para uma nova Transferência de Tecnologia Fonte: Embrapa, 2009c

Rompendo a visão fragmentada dos processos dentro da Empresa, pode-se então adotar um modelo de TT onde a inovação tecnológica ocorre de forma contínua. O modelo simplificado de $\mathrm{P} \& \mathrm{D}$ em agropecuária demonstrado na Figura 2 sugere que a inovação tecnológica começa e termina no produtor e possui como ator imprescindível o extensionista. 
Maria Gomes da Conceição Lira \& Brigitte Renata Bezerra de Oliveira

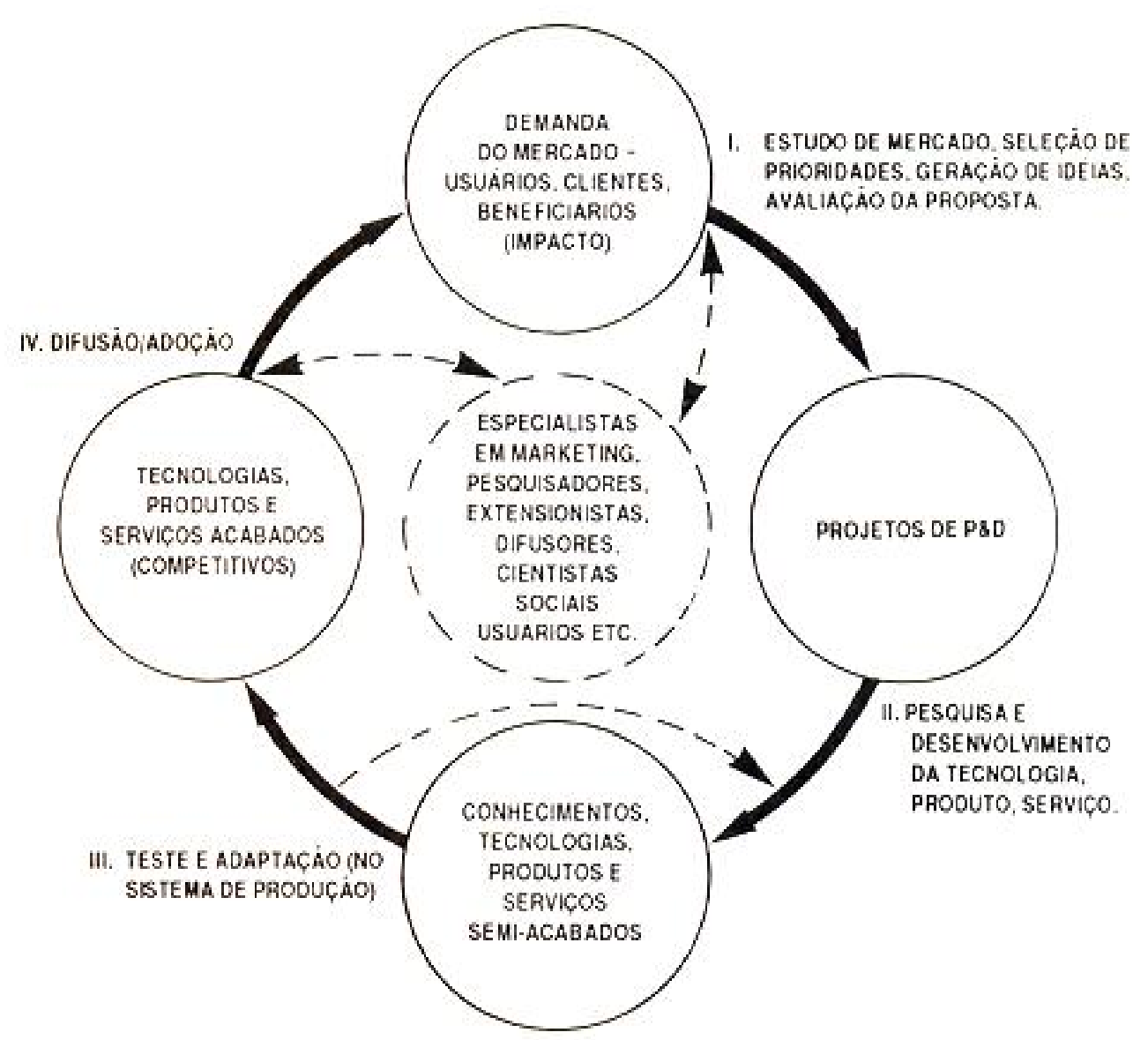

Figura 2: Modelo simplificado de P \& D em agropecuária.

Fonte: Horton, 1991 (adaptado) baseado em Booz, Allen \& Hamilton apud Embrapa, 2009c

Conclui-se portanto, que a Embrapa Semiárido tem dado grandes contribuições para o desenvolvimento do Polo Petrolina/Juazeiro e que tanto a sociedade quanto a empresa estudada sabem da necessidade de melhorias nas atividades de TT por ela desenvolvida. Foi proposto, portanto uma nova maneira de transferir conhecimento para garantir a inovação tecnológica e consequentemente mais desenvolvimento socioeconômico.

\section{Referências}

ALBAGLI, S.; MACIEL, M. L. Informação e conhecimento na inovação e no desenvolvimento local. Ci. Inf., Brasília, v. 33, n. 3, p.9-16, 2004. Disponível em <http://revista.ibict.br/index.php/ciinf/article/vi ewArticle/587> Acesso em 07 set. 2009.
BONNAL, P.; MALUF R. Políticas de desenvolvimento territorial e a multifuncionalidade da agricultura familiar no Brasil. In: Colóquio internacional de desenvolvimento territorial sustentável. Florianópolis, 2007. Disponível em: <http://www.cidts.ufsc.br/>. Acesso em 02 out. 2009

BUARQUE, C. O pensamento em um mundo terceiro mundo. In: BURSZTYN, Marcel.Para pensar o desenvolvimento sustentável. São Paulo: Brasiliense, 1993.

BUARQUE, C. O pensamento em mundo Terceiro Mundo. In: BURSZTYN, M. (org.) Para pensar o desenvolvimento sustentável. 2a. ed. São Paulo: Brasiliense, 1994.

CARVALHO, O. de; EGLER， C. A. G. Alternativas de desenvolvimento para o 
nordeste semi-árido. Fortaleza: Banco do Nordeste do Brasil, 2003. 204 p.

CROCCO, M.; HORÁCIO, F. Industrialização Descentralizada: Sistemas Industriais Locais $\mathrm{O}$ Arranjo Produtivo Moveleiro de Ubá. Contrato BNDES/FINEP/FUJB. (Nota Técnica, 38). Rede de Pesquisa em Sistemas Produtivos e Inovativos Locais, IE/UFRJ, 2001.

EMBRAPA SEMI-ÁRIDO. IV Plano Diretor da Embrapa Semi-Árido: 2008 - 2011 2023. Petrolina, 2008. 37 p. il.

EMBRAPA SEMI-ÁRIDO. Relatório de gestão 2006. Petrolina, 2006. 81p. il. Elaborado por EDUARDO A. M.; GISLENE F. B. G.; LUIZA T. DE L. B.; MAGNA S. B. DE M.; MARIA A. C. DE L.; NEIDE M. G. L.

EMBRAPA SEMI-ÁRIDO. Relatório de gestão 2007-2008. Petrolina,2009a.

EMBRAPA. Transferência de tecnologia da Embrapa: estado da arte.Apresentação em slide.Brasília, 2009c.

FÉLIX, C; HAROLDO, S. MARIA, O. No Semi-árido, Viver é Aprender a Conviver: Conhecendo o Semi-árido em Busca da Convivência. 2007 Disponível em <www.irpaa.org/br/dmdocuments/nosaviver.pdf $>$ Acesso em 26 ago. 2009

FLEURY, A.; FLEURY, M. T. L. Estratégias Empresariais e Formação de Competências: Um Quebra-Cabeça Caleidoscópico da Indústria Brasileira. 2. ed. São Paulo: Editora Atlas, 2001. 169 p.

HAGUETTE, T.M.F. Metodologia qualitativa na sociologia. Petrópolis: Vozes, 2001.

IBGE. Ministério do Planejamento, Orçamento e Gestão.Contagem da população 2007. Disponível em http://www.ibge.gov.br/home/estatistica/popula cao/contagem2007/contagem.pdf Acesso em 28 ago. 2009
LACERDA, M. A. D.; LACERDA, R. D. O Cluster da fruticultura no Pólo Petrolina/Juazeiro. Revista de Biologia e Ciências da Terra, v.4, 2004, n.1, 22 p.

LASTRES, H. M. M.;FERRAZ, J. C. Economia da Informação, do Conhecimento e do Aprendizado, em Informação e Globalização na Era do Conhecimento. Editora Campus, 1999.

LAKATOS, E. M.;MARCONI, M. Fundamentos de metodologia científica. São Paulo: Atlas, 2001.

MERRIAM, S. B. Qualitative research and case study applications in education. San Francisco: Jossey-Bass, 1998

MORAES, L. B. de. A força dos valores sócio culturais nos Arranjos Produtivos Locais(APLs) - um novo olhar sobre a espiral do conhecimento, V Encontro Latino de Economia Política da Informação, Comunicação e Cultura, Salvador, 2005. Disponível em: <http://www.gepicc.ufba.br/enlepicc/pdf/Leona rdoBarbosaDeMoraes.pdf $>$ Acesso em 24 set. 2009

SILVA, E. L; MENEZES, E.M. Metodologia da pesquisa e elaboração de dissertação. 3 . ed. Florianópolis: UFSC/LED, 2001.

SILVA, P. C. G. da; GUIMARÃES FILHO, C. Eixo tecnológico da ecorregião Nordeste. In: SOUSA, I. S. F. de (Ed.). Agricultura familiar na dinâmica da pesquisa agropecuária. Brasília, DF: Embrapa Informação Tecnológica, 2006. cap. 3. p. 109-161.

OLIVEIRA FILHO, S. F. S.; XAVIER, L. F.; COSTA, E. F. A fruticultura irrigada do Pólo Petrolina-Juazeiro e a possibilidade de acesso a novos mercados. In: IV Encontro de Economia Baiana - Políticas Públicas e Desenvolvimento Econômico, 2008, SalvadorBA. Anais do IV Encontro de Economia 
Maria Gomes da Conceição Lira \& Brigitte Renata Bezerra de Oliveira

Baiana - Políticas Públicas e Desenvolvimento Econômico, 2008.

TONETO JR., R. Proposta para avaliação dos pólos de desenvolvimento integrado. Fortaleza: Banco do Nordeste do Brasil, 2004.

YIN, Robert K. Estudo de caso: planejamento e métodos. 2. ed. Porto Alegre: Brookman, 2001. 